\title{
CHEMICAL INTERESTERIFICATION OF FRACTIONATED PALM OIL, SUNFLOWER OIL AND SOYBEAN OIL BLENDS AND ITS EFFECT
}

\author{
Vassiriki CISSE $^{1 *}$, Fahri YEMIŞÇIOĞLU ${ }^{2}$ and Merve YAZILIKAYA ${ }^{3}$ \\ ${ }^{1 *}$ Department of Food Engineering,Ege University, Campus 35100 Bornova-İzmir, Turkey \\ http://doi.org/10.35410/IJAEB.2019.276288
}

\begin{abstract}
Fractionated palm oil as such aspalm stearin, palm olein, palm mid fraction were mixed in various ratios with different polyunsaturated oils like Sunflower Oil and Soybean Oil. They were submitted to Chemical (randomization) Interesterification (CIE) reaction that is a rearrangement of fatty acids of triglycerides resulting to new triglycerides formation. However, this reaction influenced the physicochemical characteristics (Melting Point, Solid Fat Content, Triglycerides) that were assessed before and after CIE. Melting point and solid fat content values were varied due to the appearance of new triglycerides and chemical interesterification. Some triglyceride amounts were both increased and decreased and miscibility of others blends was effective. Solid Fat Content values of Palm Mid Fraction were zero to 30 and $35^{\circ} \mathrm{C}$ with Sunflower oil blend and those of Palm Olein were zero to $20,30,35^{\circ} \mathrm{C}$ with Sunflower Oil and Soybean Oil blends. The obtained values after chemical interesterification of fractionated fats and polyunsaturated oils are shown that physicochemical modification was realized and effective.
\end{abstract}

Keywords: Chemical Interesterification; SFC; SMP; Triglycerides;Fractionated Palm Oil.

\section{INTRODUCTION}

Interesterification(IE) is one the modification techniques of edible oils and fats used to facilitate the rearrangement of Fatty Acid (FA) localized or esterified to glycerol of triglyceride (Triacylglycerol, TAG). IE causes the randomization of the distribution of fatty acids in the triglyceride called intraesterification and between triglycerides called interesterification, in oils and fats until a thermodynamic equilibrium is reached (Idris et al., 2005).Thus, this leads to changes in the composition of the TAG and thus its physical characteristics. The FA exchanges resulting from IE, leads to changes in the physical characteristics of the oils and fats because in nature, they are not randomly distributed between the TAGs present. In most oils and fats, the 2position of the TAG molecules is preferentially occupied by unsaturated fatty acids (Rousseau et al., 1996) Interesterified oils/fats are recognized free of Trans Fatty Acid (TFA) during all its production contrarily to hydrogenation that has been abandoned by many manufacturers due to the appearance of TFA in hydrogenated oils and fats (Marangoni et al., 1998). IE is divided into 2 types which are really different according to used catalyst: Chemical İnteresterification (CIE) in which is used chemical catalyst like sodium methylate and enzymatic interesterification (EIE) using lipase as enzyme to produce interesterified oils or fats (Sreenivasan, 1976). CIE is used, in this study, to produce fat and to discuss the effect of this technique on different vegetable oil/fat. 
It also called random interesterification due to the fatty acid distribution on $1,2,3$ position of TAG by sodium methylate (Rai et al., 20012).

Palm Stearin (PS), Palm Olein (PO) and Palm Mid Fraction (PMF) are edible oils and fats that are obtained from crystallization-fractionation modification technique of palm oil (Gümüşkesen et al., 2010). PS and PO are issued from the first phase of palm oil fractionation. PS is harder than PO and PMF because of its high saturated acids like palmitic and stearic acids and its high melting point $\left(44-55^{\circ} \mathrm{C}\right)$ (Aini et al., 2007). Then PS is solid at body temperature, due to that, it is used in shortening, Margarine and spread fats formulation. However İt is sometimes blamed because it melts hardly at body temperature and its plasticity is also low. For this reason, PS is more often blended and/or interesterified with some polyunsaturated vegetable oils like Sunflower Oil (SFO), Soybean Oil (SO) what contain more linoleic and oleic acids (Noor et al., 1998). PO is less hard than PS and appear liquid phase at body temperature. PMF is obtained from the second phase of palm oil fractionation which is harder than PO but less than PS. It can use to produce butter or Cacao Butter Equivalent (Talbot et al., 2006).

The purposes of this work were to investigate the effect of CIEon the TAG composition, MP, FAC and SFC of PS, PMF, PO, SFO, SO and blends thereof in various ratios. The interaction of these oils and fats and their compatibility (miscibility) are also discussed. Obtained fats can use into margarine, shortening and spread formulation.

\section{MATERIALS AND METHODS}

\subsection{Samples}

Main vegetable oils used in this work were refined, bleached and deodorized SFO and SO which were obtained from one of Turkey's Oil Manufacturer called Orkide in İzmir. Others fats that used were Palm Stearin, Palm Olein and Palm Mid Fraction obtained also from IFFCO Industries,İzmir, Turkey.

\subsection{Oil/Fat Blend Preparation}

To realize chemical interesterification, different oil/fat in various ratios was blended to eliminate the crystal phase and to obtain a homogenous blend. The blend has been realized according to following ratios:

For Sunflower Oil:

SFO/PS - A(80:20) , D(70:30) , G(60:40) , J(50:50) ; SFO/PO - B(80:20), E(70:30) , H(60:40) , K(50:50) ; SFO/PMF - C(80:20), F(70:30), I(60:40), L(50:50).

\section{For Soybean Oil:}

SO/PS - A(80:20), D(70:30), G(60:40), J(50:50) ; SO/PO - B(80:20) , E(70:30) , H(60:40), $\mathrm{K}(50: 50) ; \mathrm{SO} / \mathrm{PMF}-\mathrm{C}(80: 20), \mathrm{F}(70: 30), \mathrm{I}(60: 40)$, L(50:50).

\subsection{Chemical Interesterification Reaction}


The oils were subjected to a drying at $80^{\circ} \mathrm{C}$ to eliminate water or high moisture because it can deactivate or slow down the catalyst activity (sodium metal). Sodium metal (1\%) was added to facilitate the reaction and during 30 minutes, the sample was stirred up at $120 \mathrm{rpm}$ under vacuum (25 mbar) in a rotary evaporator. Brown color appeared when the reaction was realized. After, the reaction was deactivated by hot water addition and the mixture was washed eliminating soap phase and transferred into separate funnel to continue washing. After soap phase elimination, reactant (phenolphthalein) was used to test washing efficiency. The mixture was dried under vacuum at $80^{\circ} \mathrm{C}$ and filtered by filter paper. Obtained mixture is Interesterified oil and is transferred into the bottle and stored until different analysis.

\subsection{Melting Point (SMP)}

Interesterified oils/fats were subjected to melting point to determine exactly the temperature at what the first droplet appears in the capillary tube. This is also temperature at what the fat becomes soft. According to AOCS Cc 3-25 method (2005), melting points were measured. Analysis was replicated in two and values were reported.

\subsection{Solid Fat Content (SFC)}

SFC is a ratio of solid that oil has after drying at different temperature. In this experiment, SFC was determined according to IUPAC 2.150 (b) (1987). Bruker Minispec PC 100 NMR was used and all samples were melted in water heater at $90^{\circ} \mathrm{C}$ during $30 \mathrm{mn}$ and cooled in a box containing cold water $\left(0^{\circ} \mathrm{C}-30 \mathrm{mn}\right)$. According to temperatures $20,30,35^{\circ} \mathrm{C}$, samples were reheated and SFC measured. The results were mentioned and treated.

\subsection{Fatty Acid Composition (FAC)}

FAC are amount of different fatty acids contained in the oils/fats or blended oil interesterified oils. To determine FAC, fatty acids were methylated by the addition of $0,4 \mathrm{ml} \mathrm{KOH}(2 \mathrm{~N}$ methanol $\mathrm{KOH}$ ) and $4 \mathrm{ml}$ hexane into $200 \mathrm{mg}$ sample (interesterified oil) (Garcia-Gonzalez et al., 2014). FAC were realized with Agilent technologies 7820A, GC system, Supelco SP2380, capillary column $(60 \mathrm{~m}$ length $* 0.25 \mathrm{~mm}$ id $* 0.2 \mu \mathrm{m}$ film thickness). The detector and injector temperature were set at $240^{\circ} \mathrm{C}$. The flow rate was $1.0 \mathrm{ml} / \mathrm{min}$ and column temperature was $150^{\circ} \mathrm{C}$ for all oils/fats. $1 \mu 1$ sample was injected into an Agilent technology.

\subsection{Triglycerides Profiles}

Non interesterified and interesterified fats were subjected to reversed-phase HPLC method (Gilson Villiers-el-bel, France) to determine TAG. Acetone and acetonitrile (75:25, V/V) was used and RP-18 column $(250 \mathrm{~mm} * 4 \mathrm{~mm})$ of 5 - $\mu \mathrm{m}$ size (Merck). The flow rate was $1.0 \mathrm{ml} / \mathrm{min}$ as eluent. $20 \mu \mathrm{l}$ of the sample was injected and TAG values were reported.

\subsection{Statistical Analysis}

Analyses of general linear models and response surfaces were performed using the SAS® (Cary, NC) statistical package as described by Ali and Dimick (1994). $R^{2}$ values, which indicate model fits for each of the constructed binary diagrams, were determined and were found. 


\section{RESULTS AND DISCUSSIONS}

\subsection{Fatty Acid Composition}

In this step, fatty acid composition values of fractionated oils (PS, PO, and PMF) and SFO, SOwere given in table 1 in which two parts showing fatty acid composition before chemical interesterification. Before interesterification, the oils/fats were used such as SFO and SO were composed in majority of oleic acid $38.6 \%$, linoleic acid $55.37 \%$ and oleic acid $26.23 \%$, linoleic acid $47.85 \%$ respectively Jun Jin et al. (2018) reported in their study that FAC of SFO were oleic acid $24.3 \%$ and linoleic acid $65.1 \%$; and main FAC of SO was oleic acid $24 \%$ and linoleic acid $55.4 \%$ (Luke,2005). The fractionated fats/oils contained high amount of saturated FA(palmitic acid 32-44\%, stearic acid 6-15\%) and unsaturated FA (oleic acid 28-48\%). According to SFO, SO and fractionated oils/fats FAC, the FA profile of CIE blends are not changed because It was not appeared Trans fatty acid. It shows that CIE has not affected the degree of saturation of polyunsaturated acids. But the FA of certain fats are distributed over position in TAG (Allen et al., 1996).

Table 1: Fatty acid composition of SFO, SO, fractioned fats and CIE blends

\begin{tabular}{|lcccccccccc|}
\hline & C14:0 & C16:0 & C16:1 & C18:0 & C18:1 & C18:2 & C18:3 & C20:0 & C22:0 & C24:0 \\
\hline SFO & - & - & - & 4.09 & 38.6 & 55.37 & 0.19 & 0.34 & 2.06 & 0.36 \\
SO & - & 12.99 & - & 6.04 & 26.23 & 47.85 & 5.71 & 0.74 & 0.44 & - \\
PO & - & 35.64 & - & 14.26 & 38.08 & 12.01 & - & - & - & - \\
PS & - & 43.45 & - & 11.79 & 28.10 & 16.66 & - & & - & - \\
PMF & 0.46 & 32.37 & 0.11 & 6.01 & 48.05 & 9.82 & 0.13 & 0.78 & 0.18 & 0.22 \\
SFO:PMF & 0.082 & 9.06 & 0.06 & 4.55 & 39.89 & 42.69 & 0.07 & 0.68 & 1.69 & 0.74 \\
SFO:PO & 0.16 & 13.06 & 0.095 & 3.99 & 39.34 & 42.07 & 0.08 & 0.32 & 0.50 & 0.19 \\
SFO:PS & 0.14 & 13.79 & 0.07 & 4.48 & 36.29 & 42.67 & 0.06 & 0.49 & 1.17 & 0.45 \\
SO:PO & 0.10 & 11.96 & 0.07 & 5.23 & 29.90 & 45.11 & 5.79 & 0.88 & 0.48 & 0.16 \\
SO:PS & 0.17 & 16.74 & 0.07 & 5.21 & 26.96 & 43.98 & 5.25 & 0.81 & 0.32 & 0.12 \\
SO:PMF & - & 18.51 & - & 13.83 & 28.83 & 36.04 & 2.78 & - & - & - \\
\hline
\end{tabular}

PS: palm stearin, PO: palm olein, PMF: palm mid fraction and CIE: chemical interesterification

\subsection{Slip Melting Point}

In Figure 1, theSMP of PS, PO, PMF and SO, SFO were introduced and compared between themselves. Initial Melting Points (IMP) of PS were high $\left(57.6^{\circ} \mathrm{C}\right)$ than that of PMF $\left(31^{\circ} \mathrm{C}\right)$ and $\mathrm{PO}\left(20^{\circ} \mathrm{C}\right)$, those of SO and SFO were $6^{\circ} \mathrm{C}$ and $5^{\circ} \mathrm{C}$ respectively. High melting point of PS was 
due to high presence of length chain of saturated fatty acid as palmitic acid (43.45\%) and oleic acid (28.10\%) (Pawitchaya et al., 2018). SMPof PMF also resulted to high saturated carbon chains of fatty acid (palmitic and oleic acids) (Hazirah et al., 2012). SO and SFO had low melting point due to high amount of double liaison and presence of mono- and polyunsaturated FA (linoleic, oleic acids) (Hazirah et al., 2012). IMP (PS, PMF) were high that those of NCIE blends when they were blended with SO and SFO. It was due to high amount of mono- and polyunsaturated FA.

The SMP of CIE and NCIE blends are given in Figures 2 and 3. SMP of CIE had decreased in all ratios of blend (A, B, C, D, E, F) according to the melting point of NCIE blends. That change of SMP was due to effect of chemical interesterification that rearranges the FA of TAG and due to PS, PO, PMF are diluted in polyunsaturated oils (SO and SFO). CIE melting point of SO and CIE melting point of SFO were different because of high linolenic acid amount, then double liaison (Charteris et al., 1991).

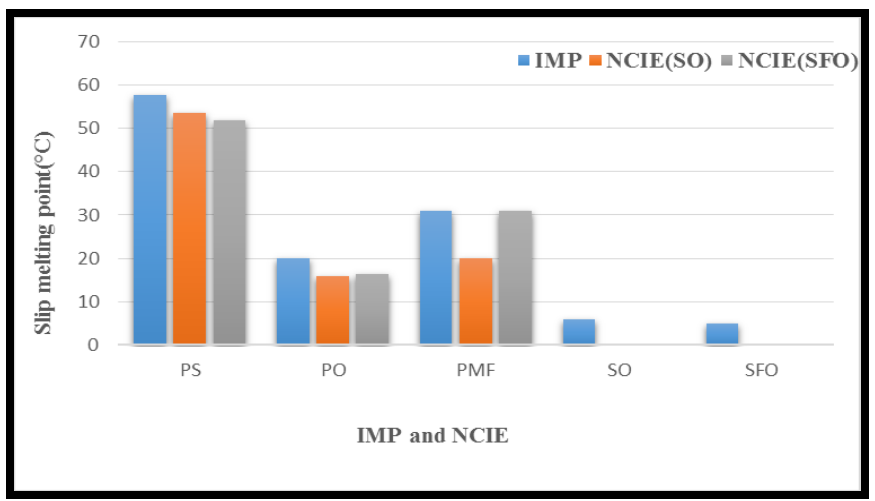

Figure 1: Slip Melting points of origin material and NCIE blends

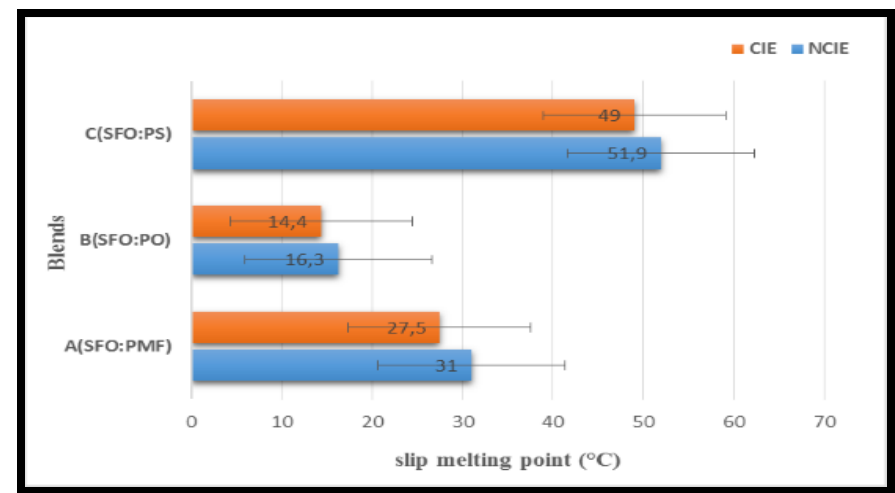

Figure 2: Slip Melting Points of NCIE and CIE blends with SFO 


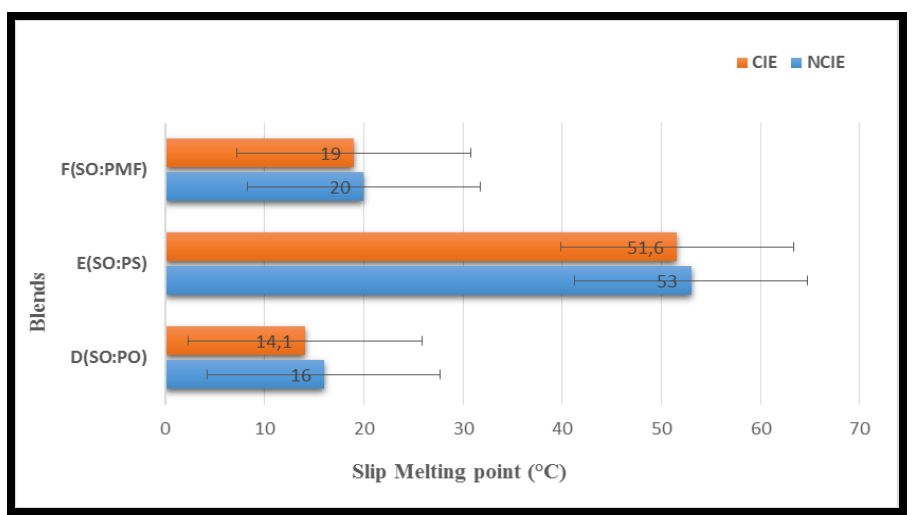

Figure 3:Slip Melting Points of NCIE and CIE blends with SO

\subsection{Solid Fat Content}

SFC is the amount of fat crystal contained in a fat or a mixture of fat that gives the physical appearance of solid products. It is also the determination of compatibility of materials contained in the mixture of saturated and unsaturated oils (mono- and polyunsaturated) (Krawczyk et al., 1996). The SFC values of the original oils /fats and interesterified mixtures are presentedin Table 2. SFC of PS had a high at all temperatures to which it was subjected. This PS value was due to triglycerides containing acids that have high melting points $\left(\mathrm{S}_{2} \mathrm{U}\right.$ or $\left.\mathrm{S}_{3}\right)$. That collaborate with the results of the studies by Hazirah (2012) and Noor (2007). SFC of PMF decreased significantly from $20^{\circ} \mathrm{C}$ to $30^{\circ} \mathrm{C}$ and was zero at $35^{\circ} \mathrm{C}$. It contained fat crystals at $30^{\circ} \mathrm{C}$ due to high amount of mono-unsaturated fatty acid and saturated fatty acid chains. PO, SO, SFO were liquid from 30 to $35^{\circ} \mathrm{C}$ because of the high number of mono- and polyunsaturated fatty acids and also their low melting point. This tendency is justified by Soekopitojo (2009).

The different SFC of fractionated palm oil blends with canola and SFO tended to decrease regard to before and after interesterification (Figure 4). With SFO, SFC value was little crystal (solid) at $35^{\circ} \mathrm{C}$ in all blending ratios, due to the presence of the high melting point of glyceride elements (PPP, POP). However SFC of SFO/PS decreased when temperature increased due to $\mathrm{SU}_{2}$ of $\mathrm{SFO}$ TAGs (more monounsaturated-polyunsaturated fatty acids in TAG). Except in the case of SFO / PS (80:20), (70:30) which increased to before and after interesterification at all temperatures $\left(20^{\circ} \mathrm{C}, 30^{\circ} \mathrm{C}, 35^{\circ} \mathrm{C}\right.$ ) (Figure 1). This increase is explained by the eutectic interaction between the oils (SFO/PS) demonstrating a better miscibility (compatibility). This is demonstrated by Dieffenbacher, (1988) and Timms, (1984).SFC of SFO/PMF decreased at all temperatures and was liquid above $30^{\circ} \mathrm{C}$ in all proportions of the mixture except in case 50:50 (figure 5).

With the mixture of SO and PS, PMF; SFC of SO/PS and SO/PMF decreased considerably at all temperatures, this is due to the high amount of U3 TAG (low melting point, polyunsaturated) in SO and solid crystal dilution in PS and PMF (Figure 6 and 7). In case of SO/PS, all the proportions of mixture tended to a linear combination except that of 50:50 which presented a sinusoidal combination under any temperatures. Noor et al. (2007)indicated in his study that the physical characteristic of the oil mixture components represented no linear combination, thus showing the interaction between the materials of the mixture. This interaction is eutectic 
interaction between SO and PS indicating better miscibility what is generally used in margarines, shortening, spread manufacturing. PO blend in SO and SFO was liquid at all temperatures and blend ratios. That was due to the presence of $\mathrm{U}_{3}$ TAGs of $\mathrm{SO}$ and SFO (mono- and polyunsaturated FA) and the dilution of low semi-crystals of PO (De clercq et al., 2012).

CIE Binary blends (SFO/PS, SFO/PMF or SO/PS, SO/PMF) were significantly affected depending on the interesterification reaction. SFC of these different interesterified mixtures decreased with respect to SFCs of Non-interesterified mixtures, because of the components of TAGs according to oils or fats. The CIE binary mixtures with SO and SFO had no influence on the one and the other in the production of interesterified fat according to Table 2.

\subsection{Triglyceride Composition}

TAG composition of SFO, SO, PS, PMF, PO and their blends before and after chemical interesterification is shown in table 3. Dominating TAG of SFO and SO were LLL, OLL, OLO, PLO, PLL and SO were LLL, OLL, PLL, OLO, PLO where L: linoleic acid, O: oleic acid, P: palmitic acid (Noor et al., 2002). The main TAG of PO and PMF were PLO, PLP, POP, PPP, POO and those of PS were PLP, POP, PPP, POO. PMF and Po contained appreciable amount of SOS and SOO. Noor et al.,(2002) [26] revealed in his study that S2U and S3 TAG were high amount in PS, PMF, PO and main U2S and U3 in SFO. Chemical interesterification realized on SFO, SO, PS , PMF and PO generated little changes in theirs TAG compositions, the main TAG of SFO as PLL, LLL, were reduced rather from 9.1 , 10.6 , 23.5 before CIE to 8.9 , 10.1 , 23.4 after CIE. Those TAG were not hardly altered. For the same fat, an increase of certain mains TAG like OLL, PLO from 27.3,8.9 to 28.7 and 9.1 respectively obtained. Change obtained was not so significant.

In the case of SO, there is not significant change between the TAG, except LLL decreased from 30.1 before CIE to 26.4 following CIE, it was hardly altered. CIE of fractionated oils/fats generated an important change in the proportion of TAG of PS in which PPP was hardly affected increasing from 19 before CIE to 24.7 after CIE. In the others (PMF, PO) the few change was observed in the proportions of main TAG.

For the binary blends of several fat (table 4), the TAG of this binary blends could not be identified because of randomization or chemical interesterification which led to appear many new TAG and the complex interaction (varying permutation). They try to have the similar carbon numbers. The TAG profiles of the interesterified blends showed more amounts than the starting blends, as the relative concentration of several TAG increased, others decreased and new TAG have been synthetized. Zainal and Yussoff (1999)found and reported this result.

Table 2:Solid Fat Contents (area \%) of CIE and NCIE blends of SFO and SO

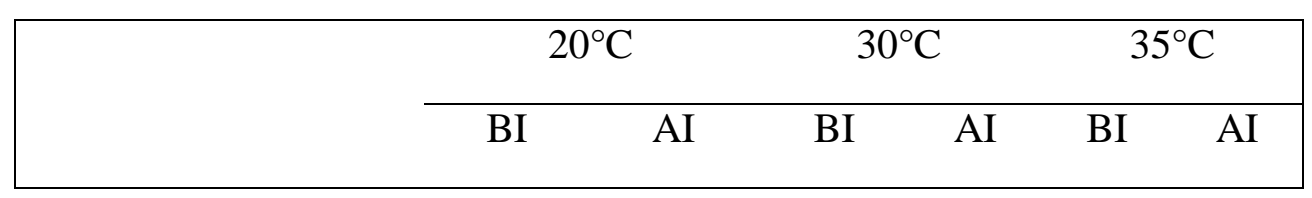




\begin{tabular}{|c|c|c|c|c|c|c|c|}
\hline \multirow[t]{4}{*}{ A(SFO:PMF) } & $80: 20$ & 1.2 & 0.5 & - & - & - & - \\
\hline & $70: 30$ & 1.8 & 0.8 & - & - & - & - \\
\hline & $60: 40$ & 2.2 & 3.1 & 0.1 & 0.4 & - & - \\
\hline & $50: 50$ & 4 & 4.5 & 0.3 & 0.8 & - & - \\
\hline \multirow[t]{4}{*}{ B(SFO:PO) } & $80: 20$ & - & - & - & - & - & - \\
\hline & $70: 30$ & - & - & - & - & - & - \\
\hline & $60: 40$ & - & - & - & - & - & - \\
\hline & $50: 50$ & - & - & - & - & - & - \\
\hline \multirow[t]{4}{*}{ C(SFO:PS) } & $80: 20$ & 8.6 & 14.9 & 5.6 & 9.9 & 4.2 & 7.5 \\
\hline & $70: 30$ & 15.4 & 9.1 & 10.5 & 6 & 8.2 & 4.4 \\
\hline & $60: 40$ & 20.8 & 20 & 13.6 & 13 & 10.9 & 9.7 \\
\hline & $50: 50$ & 27.3 & 24.1 & 18.3 & 14.8 & 14.4 & 11.2 \\
\hline \multirow[t]{4}{*}{ D(SO:PO) } & $80: 20$ & - & - & - & - & - & - \\
\hline & $70: 30$ & - & - & - & - & - & - \\
\hline & $60: 40$ & - & - & - & - & - & - \\
\hline & $50: 50$ & - & - & - & - & - & - \\
\hline \multirow[t]{4}{*}{ E(SO:PS) } & $80: 20$ & 8.2 & 7.8 & 5.1 & 4.8 & 4 & 3.6 \\
\hline & $70: 30$ & 13.4 & 13.2 & 8.3 & 7.8 & 6.3 & 6.1 \\
\hline & $60: 40$ & 18.6 & 18.3 & 11.2 & 11.4 & 8.6 & 8.4 \\
\hline & $50: 50$ & 25 & 12 & 15.5 & 5.3 & 11.9 & 3.9 \\
\hline \multirow[t]{4}{*}{ F(SO:PMF) } & $80: 20$ & 0.9 & 0.6 & 0 & 0.1 & - & - \\
\hline & $70: 30$ & 2.2 & 2.4 & 0.3 & 0.3 & - & - \\
\hline & $60: 40$ & 3.2 & 3.3 & 0.6 & 0.5 & - & - \\
\hline & $50: 50$ & 5 & 4.6 & 0.9 & 1.1 & - & - \\
\hline PS & & \multicolumn{2}{|c|}{67.5} & \multicolumn{2}{|c|}{46.8} & \multicolumn{2}{|c|}{37.7} \\
\hline
\end{tabular}




$\mid$\begin{tabular}{lccc} 
PMF & 23.7 & 3.4 & - \\
SO & - & - & - \\
SFO & - & - & - \\
\hline
\end{tabular}

AI: after interesterification, BI: before interesterification, NCIE: Non chemical interesterification, CIE:chemical interesterification

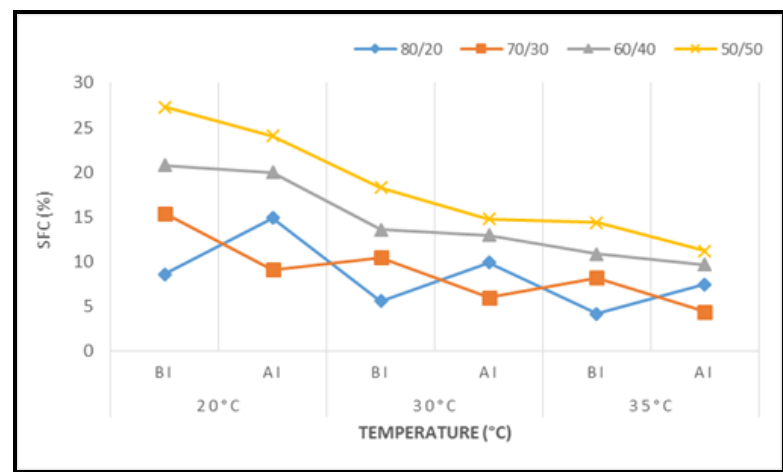

Figure 4: Solid Fat content of SFO/PS blends and $\mathrm{CIE}$ according to blending ratio

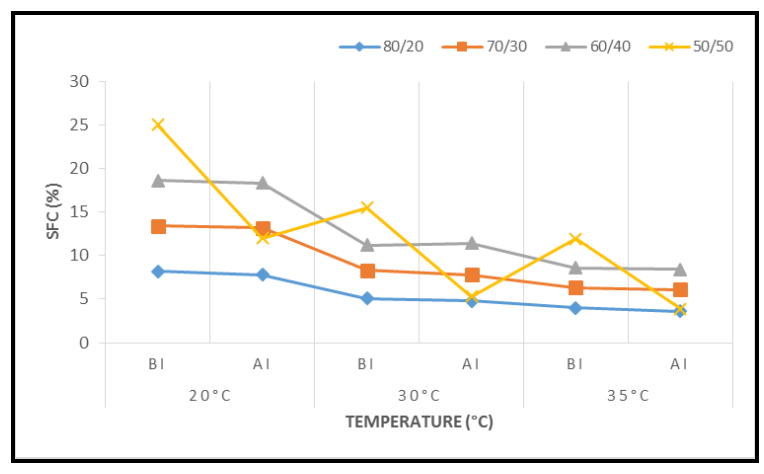

Figure 6: Solid Fat content of SO/PS blends and CIE according to blending ratio

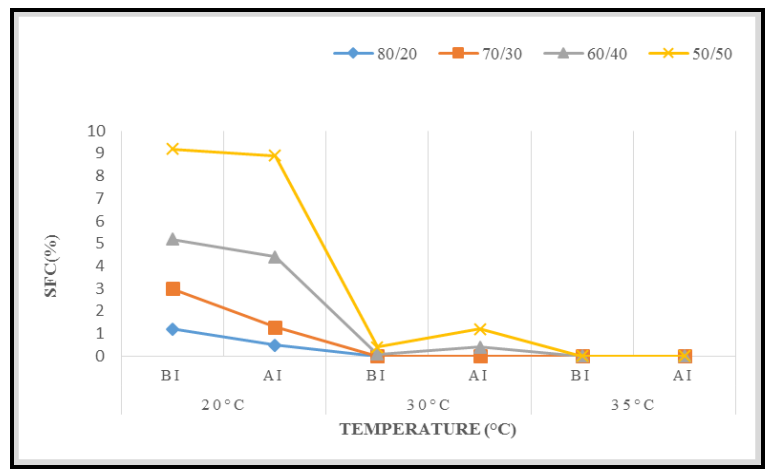

Figure 5: Solid Fat content of SFO/PMF blends and CIE according to blending ratio

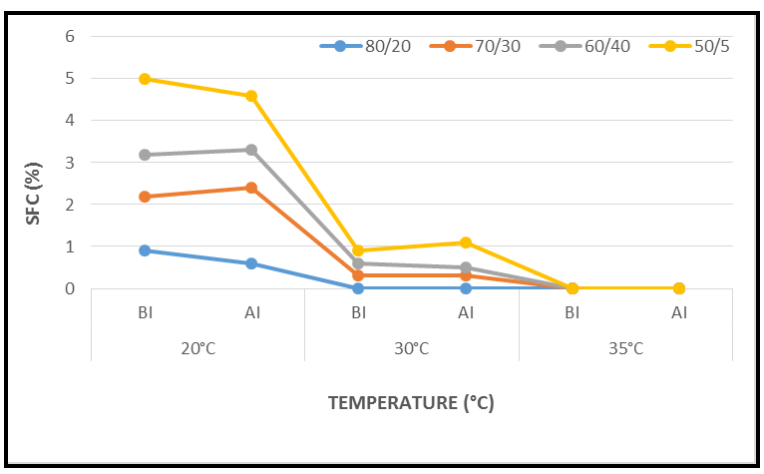

Figure 7: Solid Fat content of SO/PMF blends and CIE according to blending ratio 
Vol. 4, No. 03; 2019

ISSN: $2456-8643$

Table 3: Triglyceride composition (area \%) of SFO, SO, Palm Stearin, Palm olein (PO) and Palm Mid Fraction (PMF) before (NCIE) and after (CIE) chemical interesterification

\begin{tabular}{|lcccccccccc|}
\hline & \multicolumn{2}{c}{ SFO } & \multicolumn{2}{c}{ SO } & \multicolumn{2}{c}{ PS } & \multicolumn{2}{c}{ PMF } & \multicolumn{2}{c|}{ PO } \\
\cline { 2 - 10 } & NCIE & CIE & NCIE & CIE & NCIE & CIE & NCIE & CIE & NCIE & CIE \\
LLL & 23.5 & 23.4 & 30.1 & 26.8 & - & - & - & - & - & - \\
LLM & - & - & - & - & - & - & - & - & - & - \\
MMM & - & - & - & - & - & - & - & - & - & - \\
OLL & 27.3 & 28.7 & 29.3 & 29.1 & - & - & 0.7 & 0.8 & 0.9 & 1.0 \\
PLL & 9.1 & 8.9 & 7.9 & 7.6 & 0.5 & 0.2 & 1.4 & 1.4 & 2.8 & 2.4 \\
OLO & 10.6 & 10.1 & 9.5 & 10.6 & 0.6 & 0.4 & 3.7 & 4 & 5.2 & 5.8 \\
PLO & 8.9 & 9.1 & 9.2 & 9.3 & 0.4 & 0.3 & 7.9 & 8.9 & 10.9 & 11.3 \\
MOO & - & - & - & - & - & - & - & - & - & - \\
PLP & 0.3 & 0.2 & 0.15 & 0.1 & 6.8 & 6.5 & 7.1 & 7.1 & 7.1 & 7.2 \\
MOP & - & - & - & - & - & - & - & - & - & - \\
POP & 0.4 & 0.6 & 0.4 & 0.6 & 37.6 & 37.8 & 26.9 & 26.8 & 23 & 23.2 \\
POS & 0.2 & 0.2 & 0.3 & 0.4 & 0.8 & 0.7 & 6.0 & 5.9 & 3.7 & 3.5 \\
SOS & - & - & - & - & - & - & 0.7 & 0.6 & 0.5 & 0.4 \\
PPP & 0.6 & 1.0 & 1.0 & 1.5 & 19 & 24.7 & 12.1 & 12.0 & 7.9 & 7.6 \\
OOO & - & - & 2.8 & 2.7 & - & - & 4.9 & 4.8 & 6.5 & 7.1 \\
POO & 3.7 & 3.8 & 4 & 4.2 & 17 & 17.7 & 22.1 & 21.9 & 24.6 & 24.3 \\
SOO & 0.9 & 0.4 & 0.6 & 0.6 & 2 & 1.7 & 1.7 & 1.6 & 1.9 & 2 \\
PPS & 0.2 & 0.5 & 0.3 & 0.4 & 4.2 & 5 & 3.6 & 3.5 & 2.2 & 2.1 \\
\hline
\end{tabular}


Vol. 4, No. 03; 2019

ISSN: $2456-8643$

Table 4: Triglyceride composition (area \%) of SFO. SO. Palm Stearin (PS). Palm olein (PO) and Palm Mid Fraction (PMF) blends before (NCIE) and after (CIE) chemical interesterification

\begin{tabular}{|lccccccccccccc|}
\hline & \multicolumn{2}{c}{ SO/PS } & \multicolumn{2}{c}{ SO/PMF } & \multicolumn{2}{c}{ SO/PO } & \multicolumn{2}{c}{ SFO/PS } & \multicolumn{2}{c}{ SFO/ PMF } & \multicolumn{2}{c}{ SFO/PO } \\
\cline { 2 - 6 } & NCIE & CIE & NCIE & CIE & NCIE & CIE & NCIE & CIE & NCIE & CIE & NCIE & CIE \\
\hline LLL & 17.0 & 4.0 & 23.0 & 7.6 & 15.8 & 13.4 & 20.1 & 16.1 & 19.9 & 9.8 & 18.9 & 5.1 \\
LLM & - & - & - & - & - & - & - & - & - & - & - & - \\
LMM & - & - & - & - & - & - & - & - & - & - & - & - \\
MMM & - & - & - & - & - & - & - & - & - & - & - & - \\
OLL & 17.9 & 11.8 & 25.1 & 16.8 & 15.3 & 5.1 & 19.8 & 16.3 & 18.1 & 17.3 & 18.1 & 3.9 \\
PLL & 6.0 & 10.9 & 1.4 & 0.8 & 5.6 & 7.0 & 9.1 & 12.8 & 8.9 & 11.9 & 5.0 & 3.5 \\
OLO & 5.3 & 19.1 & 0.9 & 0.1 & 6.3 & 15.1 & 9.3 & 10.2 & 9.0 & 12.0 & 8.0 & 12.3 \\
PLO & 6.8 & 3.0 & 4.1 & 2.2 & 6.1 & 14.3 & 8.7 & 14.1 & 7.8 & 15.4 & 7.6 & 13.2 \\
MOO & - & - & - & - & - & - & - & - & - & - & - & - \\
PLP & 5.0 & 9.7 & 4.0 & 1.8 & - & - & 1.9 & 4.5 & 2.0 & 5.4 & 2.1 & 5.2 \\
MOP & - & - & - & - & - & - & - & - & - & - & - & - \\
POP & 23.0 & 20.5 & 13.3 & 4.8 & 15.9 & 14.9 & 12.3 & 4.3 & 13.0 & 4.1 & 16.1 & 6.3 \\
POS & 3.9 & 1.8 & 2.9 & 14.4 & 2.9 & 3.0 & 1.3 & 1.2 & 1.2 & 1.2 & 2.3 & 2.0 \\
SOS & - & - & 0.1 & 7.2 & 0.3 & 0.1 & - & - & 0.2 & - & 0.5 & 0.1 \\
PPP & 8.3 & 4.8 & 1.5 & 3.0 & 8.3 & 5.2 & 4.0 & 1.9 & 3.9 & 1.2 & 3.9 & 3.7 \\
OOO & 2.1 & 0.1 & 1.2 & 0.2 & 2.4 & 0.5 & 1.8 & 0.6 & 1.5 & 0.3 & 2.6 & 0.7 \\
POO & 6.9 & 10.1 & 8.0 & 1.3 & 5.8 & 12.5 & 7.1 & 7.2 & 6.9 & 7.0 & 9.9 & 10.1 \\
SOO & 1.2 & 1.2 & 1.0 & 3.1 & 1.3 & 1.0 & 0.8 & 0.8 & 0.6 & 0.5 & 0.5 & 0.4 \\
PPS & 0.4 & 0.3 & 10.0 & 12.1 & 0.2 & 0.3 & 2.5 & 1.5 & 2.2 & 2.3 & 2.0 & 1.7 \\
\hline
\end{tabular}


Vol. 4, No. 03; 2019

ISSN: $2456-8643$

\section{CONCLUSION}

This study has demonstrated that the binary blends of several oils (SFO, SO and/or fractionated palm oil) and with random interesterification (CIE) could provide new fat products that are free trans fatty acid and having desired SFC,SMP, FA and triglycerides.

CIE is the method that permitted to modify the characteristics of origin oils/fats, blends and to improve the compatibility (miscibility) of oils and blend materials. Those binary blends could be used in margarine, shortening and spread formulation.

\section{REFERENCES}

[1] Idris, N.A., and N.L.H.M. Dian,Interesterified palm products as alternatives to hydrogenation. Asia pacific Journal of clinic nutrition, 14(4), pp.396-401, 2005.

[2] Rousseau, D., Forestiere, K. Hill, A. R., \& Marangoni, A. G.,Restructuring butter fat through blending and chemical interesterification.1.Melting behavior and triacylglycerol modification. Journal of the American oil chemists' society, 73, pp. 963-972, 1996.

[3] Marangoni, A.G. \& Rousseau D., Chemical and enzymatic modification of butterfat and butterfat canola oil blends. Food Research international, 31(8), pp.595-599, 1998.

[4] Sreenivasan, B., İnteresterification of fats. J. American oil chem. Soc. 55, pp.796-805, 1976.

[5] Rai Muhammad Amir, Muhammad AsimAhabbir, MoazzamRafiq khan, ShahzadHussain,Interesterification of fats and oils. A review. Pak. J. Food. Sci. 22(3), pp.143153, 2012.

[6] Gümüşkesen A. S.,Yemişçioğlu ,Bitkisel sıvıvekatıyağüretimteknolojisi. Meta Basım. edt 1. 975-94208,2010.

[7] Aini, I. N. \&Miskandar, M.S, Utilisationn of palm oil and palm products in shortening and margarines. Eur. J. Lipidscitechnolo. 109(4), pp.422-432, 2007.

[8] H.M.D Noor Lida, A.R. Md. Ali,Physicochemical characteristics of palm based oil blends for the production of reduced fat spreads. J. Am. Oil chem. Sc. 75, pp.1625-1631, 1998.

[9]Geoff Talbot, Kevin W. Smith, Fred W. Cain,Solvent fractionation of palm oil. İnform. 17(5), pp.324-326, 2006.

[10] American Oil Chemists' Society,Official Methods and recommendedpractices of the AmericanOil Chemists' Society. Champaign Illinois, 2005.

[11] IUPAC Norm version, 2.150 (ex 2.323). Solid content determination in fat by NMR (low Resolution NMR), 1987.

[12] Garcia-Gonzalez, D.L., Aparicio-Ruiz, R. And Morales, M.t., Chemical characterization of organic and non-organic virgin olive oils, OCL, 21(5), D506, 2014.

[13] Md. Ali, A.R., and P.S. Dimick, Thermal Analysis of Palm Mid-Fraction, Cocoa Butter, and Milk Fat Blends by Differential Scanning Calorimetry, J. Am. Oil Chem. Soc. 71, pp.299-302, 1994.

[14] Juan Jui, Liang tie, LigenZheng, Min Cheng, Dan Xie, QuigzheJui\&Xingguowang, Characteristic of palm mid fraction produced from different fractionation paths and their potentiel usages. İntern. Journal of food properties. (21), pp.58-69, 2018.

[15]Luke Aaron Farno, Oil and fatty acid profiles of soybeans(Maturity group IV, V, and VI). Fac. of the graduation college of the Oklahoma state university, pp.1-2,2005. 
[16] D. A. Allen,İnteresterification- A vital tool for the future? Lipid technology. (8), pp.1115,1996 .

[17] Pawitchaya Podchong, chui Ping tan, SopRKSonwai, Derick Rousseau, Composition and crystallization behavior of solvent-fractionated palm stearin. Int. Journal of food properties. (21), pp.496-509, 2018.

[18] SitiHazirah, M.F., Norizzah, A.R. And Zaliha, O., Effect of chemical interesterification on the physical properties of palm stearin, PKO, SFO blends. The Malaysia J. of analytical Sc. 16(3), pp.297-308, 2012.

[19] W. P. Charteris, M. K. Kekeogh, Fats and oils in table spreads. Lipid Technol.(3), pp.16-22, 1991.

[20] G. S. Krawczyk, G. S. Buliga, D. T. Bertrand, W. M. Humpreys, Reviewing the technology of low fat spreads. Inform. (7), pp.635-639, 1996.

[21] Noor L. H. M., K. S, Nor A.I., Effect of chemical interesterification on TAG and SFC of PS, SFO and PKO blends. Eur. J. Lipid Sci, technol. (109), pp.147-156, 2007.

[22] S. Soekopitojo, P. Hariyadi, t. R. Muchtadi and N. Andarwlan., Enzymatic interesterification of palm mid fraction blends for the production of cocoa butter equivalents. AS. J. Food Ag-Ind 2(04), pp.807-816, 2009.

[23] Dieffenbacher, The optimal use of oils and fats in foods. Nestec Ltd. Technical Assistance, Vevey (Switzerland). Pp. 21-31, 1988.

[24] Timms, R. E., Phase behavior of fats and the mixture. Progress in Lipid Research, (23), pp.1-38, 1984.

[25] Nathalie De clercq, Sabine D., Mai t. N., V. Gibson, Koen D., Enzymatic interesterification of Po and fraction: Monitoring the degree of interesterification using different methods. JAOCS. (89) pp.219-229, 2012.

[26] Noor L. H. M. D. , K. Sundram, W. L. Siew , A. Aminah, S. Mamot,TAG composition and SFC of PO, SFO, PKO blends before and after CIE. JAOCS. Vol79 No.11, 2002. 